\title{
Pharmacological Studies on the Experimental Caries of Rats : \\ Part IX Effects of Various Herb Drugs on the Caries Formation
}

\author{
by \\ Toyoyuki TAMURA, ${ }^{*}$ Masafumi KOBAYASHI, ${ }^{*}$ Tetsu WATANABE*
and Junji SUNOUCHI*
}

Introduction

Of many new facts brought to light in the pharmacological area in recent years, one of the prime interest is that which is concerned with sex hormones found in plants and herbs. YAMASHITA et al., [1] reported the fact that among the women workers engaged on the plantation of hops there are often observed phenomena such as the reduction of menstrual cycle, increase in the menstrual discharge, abnormal growth of reproductive organs and so on. Hitherto it was already made clear that most female flowers contain essential oil, myrcene, humulene, myrcenolester, luparone, luparol, lupulone, humulone and resin but the existence of hormones in plants has not been noticed till recent years.

TSUCHIYA and his associates [2] discovered a hormone-like substance in the rice bran and its extract oil which is a compound of pherula acid and triterpen-alcohol $\left(\mathrm{C}_{40} \mathrm{H}_{53} \mathrm{O}_{3}-\mathrm{C}_{41} \mathrm{H}_{60} \mathrm{O}_{4}\right)$ and is found to be efficacious for the patients of menopause syndrome. Following this up, TAMURA [3] reported that an injection of $15 \mathrm{mg}$ of this compound into castrated female rats was sufficient to restore them an estrous cycle. Recently the present authors [4] have given their findings that olive oil contains a substance which is more effective than testosterone in exciting the testes activity.

These facts provide evidence that there are contained hormone-like substances, if not hormones in the precise connotation, in many plants and herbs and the present paper is concerned with another step forward in the direction.

\section{Materials and Method}

For experimental purposes a preparation was made of the following composition (Table 1) and the addition of honey, sugar and millet-jelly was meant as sweetening agents. This preparation is to be referred to as A Additive.

And another preparation was prepared from powdered salamanders which had the following chemical properties. This is to be referred hereafter to as B Additive.

In addition to the main chemical properties given above, these two additive preparations contained minute quantities of $\mathrm{Ca}, \mathrm{Mg}, \mathrm{P}, \mathrm{Na}$ and $\mathrm{F}$.

* 田村 豊幸, 小林 雅文, 渡辺 徹, 須之内 淳二: Department of Pharmacology, Nihon Univ. School of Dentistry (Chief: Prof. Mikio Sato) 
TABLE 1

Chemical Composition of Preparation Used

\begin{tabular}{l|lr}
\hline \multicolumn{1}{c|}{ Ingredients } & \multicolumn{2}{c}{ Chief constituetns } \\
\cline { 2 - 3 } Actinidae Fructus & $\begin{array}{l}\text { Matatabi acid } \\
\text { Panaxylon, panaxin, } \\
\text { Extractum Ginseng }\end{array}$ & 100.0 \\
Epimedii Herba & Alkaloid & 1.0 \\
Honey & Fruit sugar & 1.5 \\
Sugar & Saccharide, iron, calcium \\
Millet-jelly & $\begin{array}{l}\text { Saccharide, phosphorus, } \\
\text { calcium }\end{array}$ & 100.0 \\
& & 40.0
\end{tabular}

TABLE 2

Chemical Composition of

Powdered Salamanders

Experimental objectives: Of various theories purporting to explicate the formational mechanism of caries, the two facts seem to be irrefutable. One is an external factor derived from the intake of sugar and such things and the other an internal factor mainly based on the endocrinological considerations. Some specific sex hormones are known to be involved in the caries mechanism; testosterone, hexesterol, progesterone are contributive to the development of caries, while syloxine and parotin are inhibitive of the phenomenon. For this reason, healthy male and female rats, weighing anywhere from 30 to $50 \mathrm{~g}$, were fed on two kinds of feed; rice and Oriental feed. The feed was each mixed with these additives in two different concentrations of $2 \mathrm{cc}$ and $6 \mathrm{cc}$ solved in $200 \mathrm{cc}$ water. A group of males and another of females were respectively fed on these feed mixtures and their results were compared with those of control after 100 days. When the animals were put to death at the completion of experimental feeding on the 100th day, both the upper and lower jaws were carefully examined by
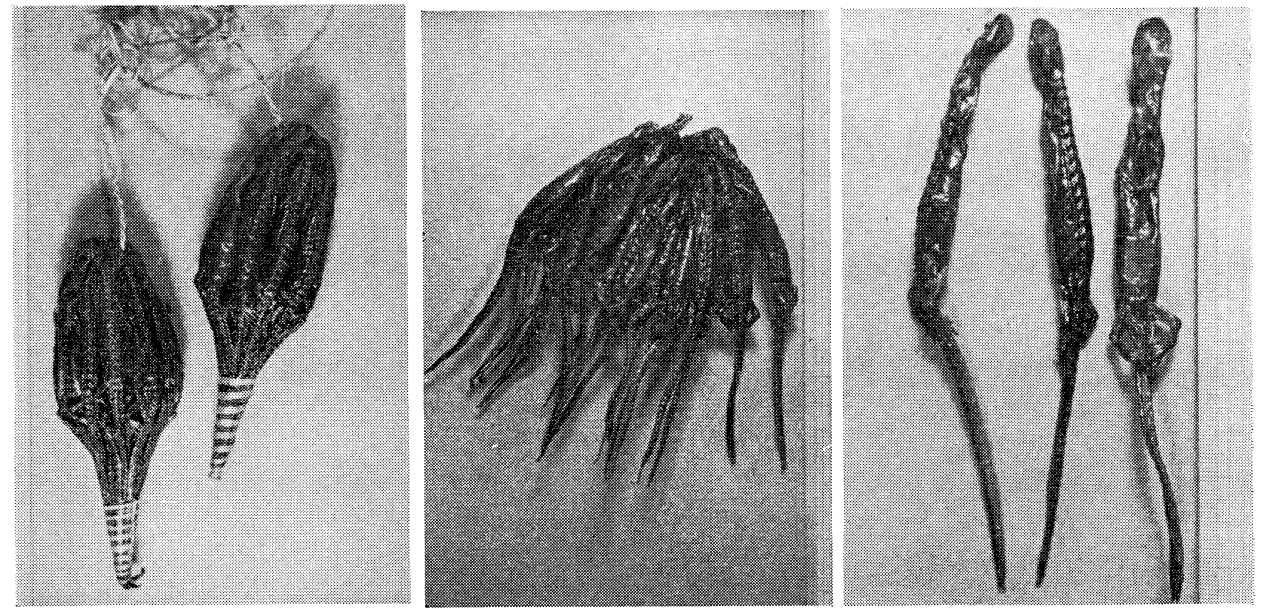

Fig. 1. Dried Salamanders Used for the Study

Right: Individual ones

Middle: Salamanders grouped together.

Left : Tied in a tight packet and they are usually sold in this form 
means of the magnifying glass to observe the formation of caries and determine the degree of it. In the degree determination, a fourfold system was adopted in which $\mathrm{C}_{1}$ referrs to the appearance of black spots along the occlusional surface furrow, $\mathrm{C}_{2}$ a somewhat advanced stage where fissures appear, $\mathrm{C}_{3}$ a further degeneration where carious pockets are clearly observable and $\mathrm{C}_{4}$ the crown portion has entirely disappeared and the residue is exposed. The caries count was interpreted in terms of the total number of molars to calculate an intensity of caries degree. On the 45th day, a midway to the end of our experiments, we measured an increase in their weight so as to see effects owing to the additives used. Therefore, the following three points received our prominent attention throughout the present study.

1) Possible effects of additives on the caries formation.

2) Possible effects of additives on the various organ increments.

3) Effects on the weight increment on the part of experimental animals owing to the additives.

\section{Results}

The findings obtained after the completion of a 100-day study are to be given under the three headings as referred to above.

\section{Possible Effects of Additives on the Caries Formation.}

Figs. 2 and 3 respectively give the results under this test. In the former case in which the Oriental feed was used, it has been made clear that the administration of the Oriental feed has effects in keeping in check the development of caries. What is particularly worthy of notice is that the caries formation in male rats was inhibited as much as one-third of the ordinary occurrence compared with control. It is to be

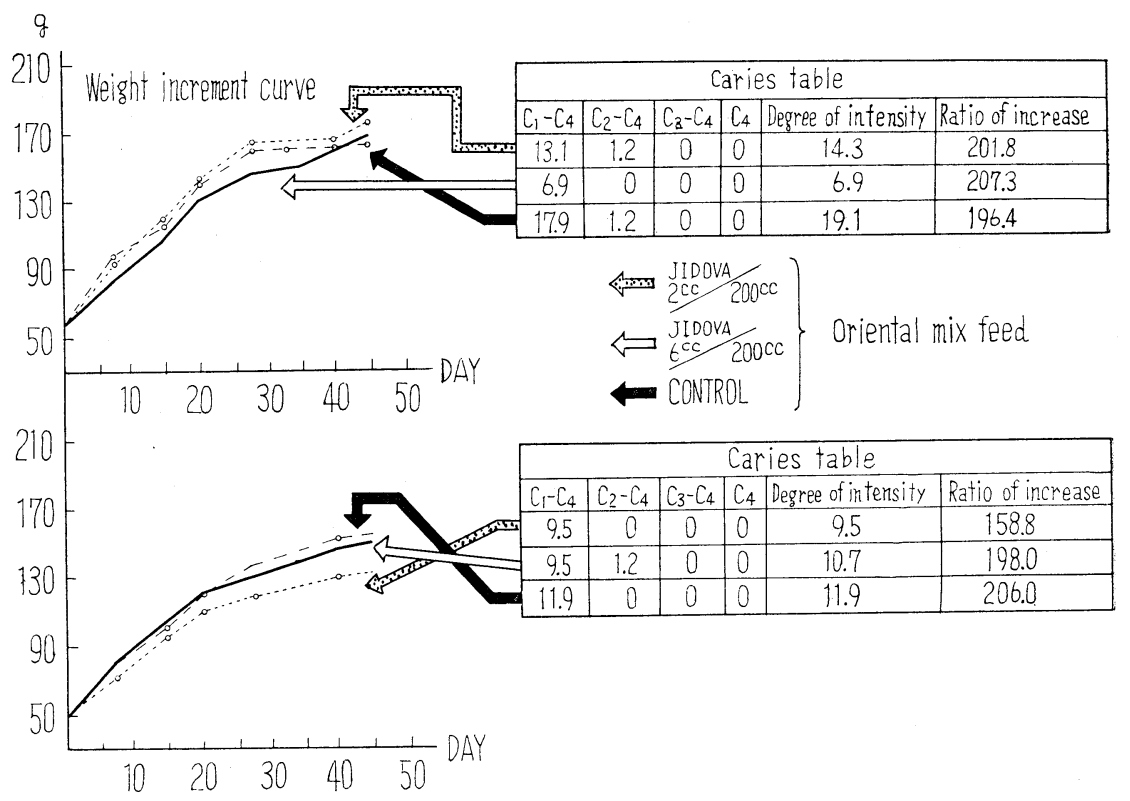

Fig. 2. Effects of Oriental Feed in the Caries Formation 

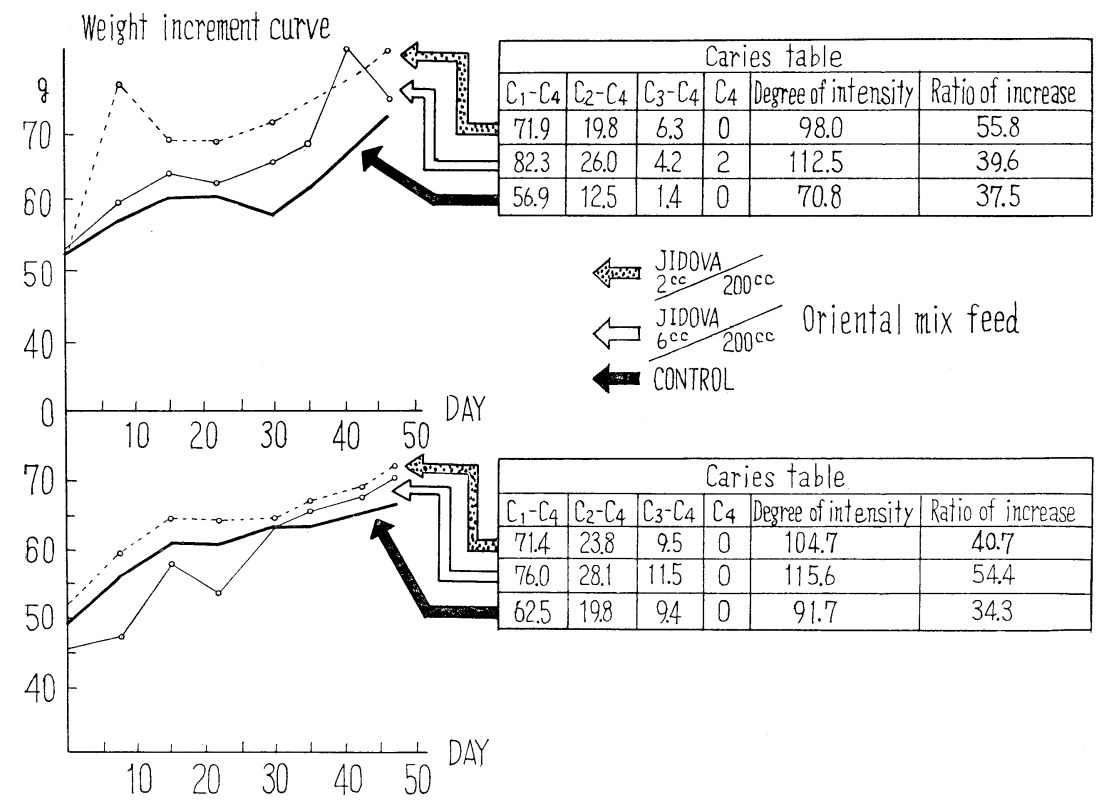

Fig. 3. Effects of Polished Rice on the Caries Formation

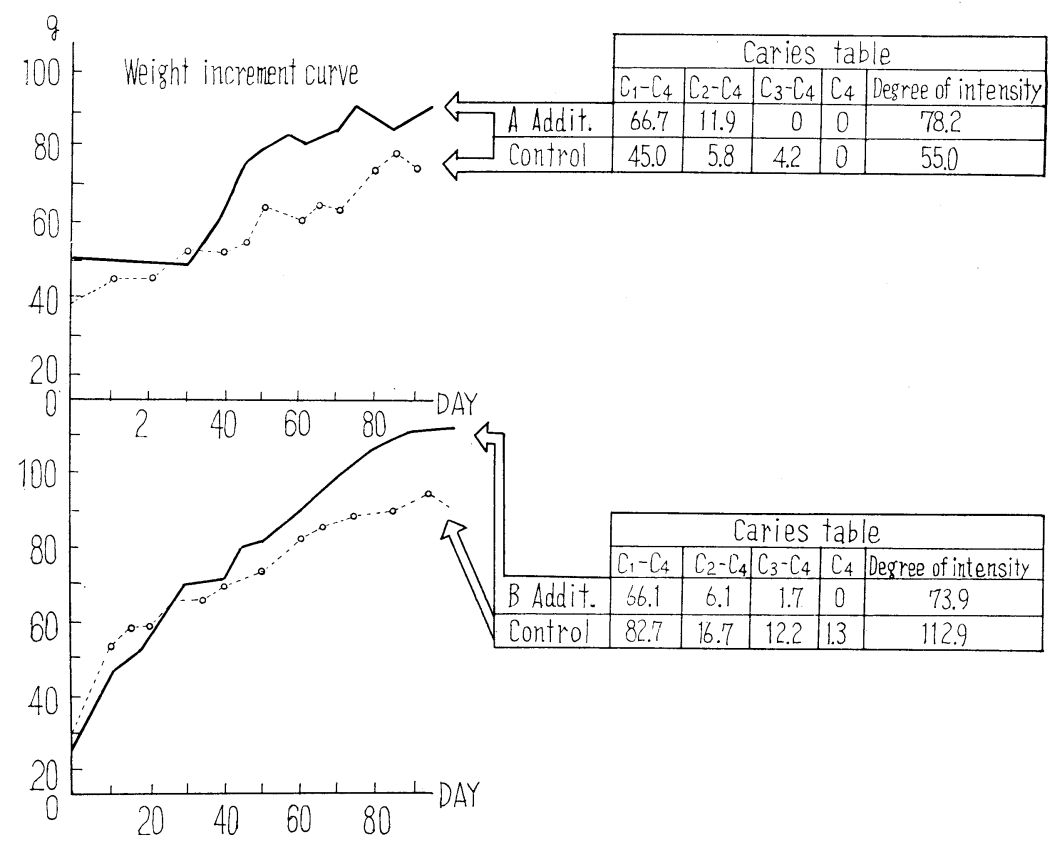

Fig. 4. Effects of Additives on the Formation of Caries

Top : Glycrrhizae Radix

Below : Powdered salamanders 


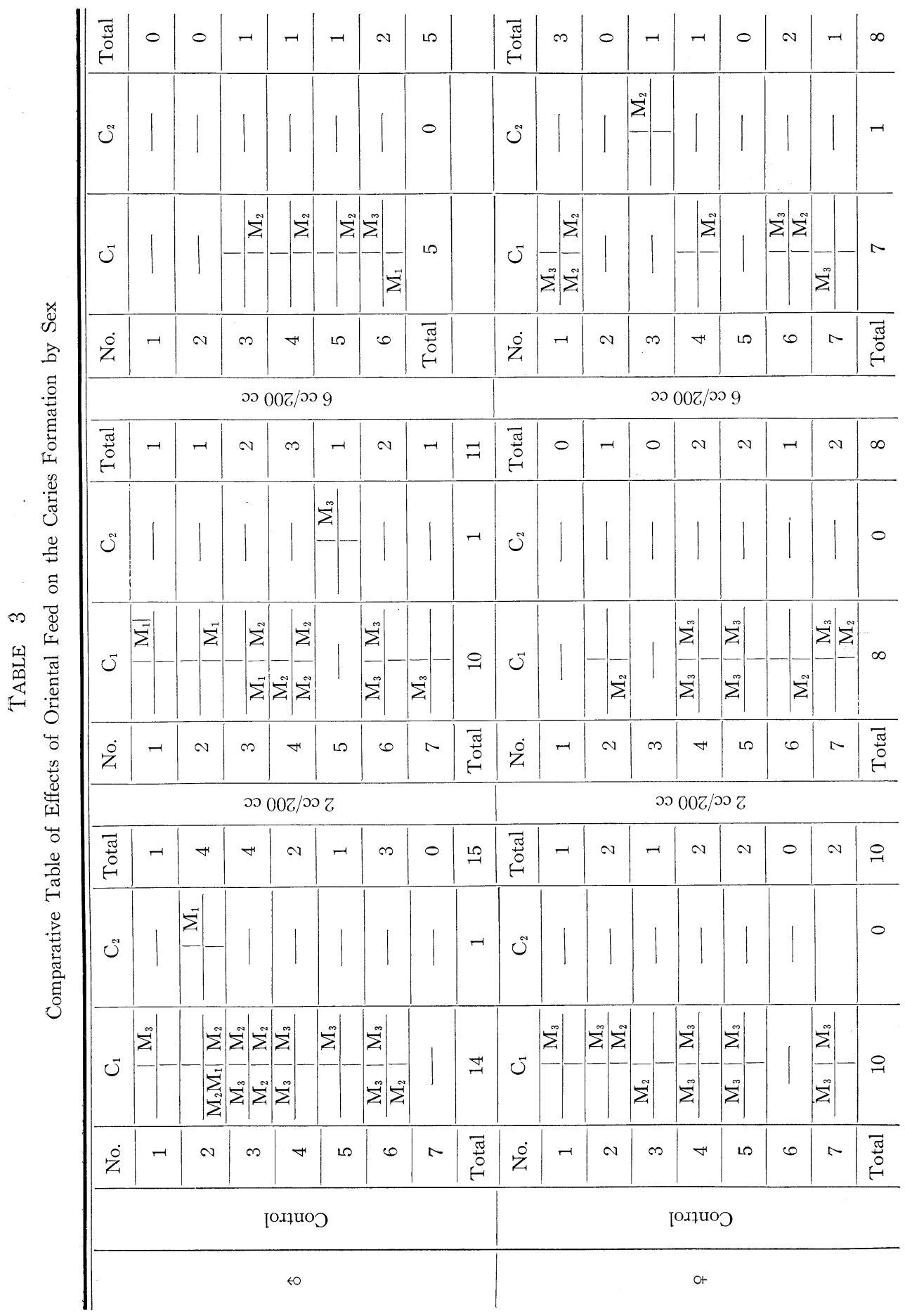


TABLE 4

A Table showing the Caries Formation and its Degrees of Intensity in 7 Experimental Rats (A Additive)

\begin{tabular}{|c|c|c|c|c|c|c|c|}
\hline \multicolumn{8}{|c|}{ A Additive (Glycrrhizae Radix) } \\
\hline No. & Weight & \multicolumn{2}{|c|}{$\mathrm{C}_{1}$} & $\mathrm{C}_{2}$ & $\mathrm{C}_{3}$ & \multirow{2}{*}{$\mathrm{C}_{4}$} & \multirow{2}{*}{$\begin{array}{c}\text { Total } \\
7\end{array}$} \\
\hline 1 & $89 \mathrm{~g}$ & $\frac{\mathrm{M}_{2} \mathrm{M}_{1}}{\mathrm{M}_{2}}$ & $\mathrm{M}_{1} \mathrm{M}_{2}$ & \begin{tabular}{l|l}
$\mathrm{M}_{1}$ & $\mathrm{M}_{2}$ \\
\end{tabular} & - & & \\
\hline 2 & 103 & $\begin{array}{c}\mathrm{M}_{2} \mathrm{M}_{1} \\
\mathrm{M}_{2}\end{array}$ & $\begin{array}{c}\mathrm{M}_{1} \mathrm{M}_{2} \\
\mathrm{M}_{2} \\
\end{array}$ & $\mathrm{M}_{1} \mid \mathrm{M}_{1}$ & - & - & 8 \\
\hline 3 & 86 & $\frac{\mathrm{M}_{3} \mathrm{M}_{2} \mathrm{M}_{1}}{\mathrm{M}_{2} \mathrm{M}_{1}}$ & $\frac{\mathrm{M}_{1} \mathrm{M}_{2} \mathrm{M}_{3}}{\mathrm{M}_{2}}$ & $\mathrm{M}_{1}$ & - & - & 10 \\
\hline 4 & 100 & $\begin{array}{c}\mathrm{M}_{1} \\
\mathrm{M}_{2} \mathrm{M}_{1}\end{array}$ & $\mathrm{M}_{1}$ & $\mathrm{M}_{2}$ & - & - & 5 \\
\hline 5 & 83 & $\begin{array}{c}\mathrm{M}_{2} \mathrm{M}_{1} \\
\mathrm{M}_{2} \mathrm{M}_{1}\end{array}$ & & $\frac{\mathrm{M}_{1}}{\mathrm{M}_{1} \mathrm{M}_{2}}$ & - & - & 7 \\
\hline 6 & 82 & $\begin{array}{l}\mathrm{M}_{3} \mathrm{M}_{1} \\
\mathrm{M}_{2} \mathrm{M}_{1}\end{array}$ & $\frac{\mathrm{M}_{1} \mathrm{M}_{2} \mathrm{M}_{3}}{\mid \mathrm{M}_{1} \mathrm{M}_{2}}$ & - & - & - & 9 \\
\hline 7 & 85 & $\frac{\mathrm{M}_{2} \mathrm{M}_{1}}{\mathrm{M}_{3} \mathrm{M}_{2} \mathrm{M}_{1}}$ & $\frac{\mathrm{M}_{1} \mathrm{M}_{2} \mathrm{M}_{3}}{\mathrm{M}_{2}}$ & $\mathrm{M}_{1}$ & - & - & 10 \\
\hline \multicolumn{2}{|c|}{ Total } & \multicolumn{2}{|c|}{46} & 10 & 0 & 0 & 56 \\
\hline \multicolumn{8}{|c|}{ Control } \\
\hline No. & Weight & \multicolumn{2}{|c|}{$\mathrm{C}_{1}$} & $\mathrm{C}_{2}$ & $\mathrm{C}_{3}$ & $\mathrm{C}_{4}$ & Total \\
\hline 1 & $47 \mathrm{~g}$ & $\mathrm{M}_{1}$ & $\mathrm{M}_{1}$ & - & \begin{tabular}{l|l}
$M_{2}$ & $M_{2}$
\end{tabular} & - & 4 \\
\hline 2 & 995 & $\frac{\mathrm{M}_{3} \mathrm{M}_{2} \mathrm{M}_{1}}{\mathrm{M}_{3} \mathrm{M}_{2} \mathrm{M}_{1}}$ & \begin{tabular}{|c|}
$\mathrm{M}_{1} \mathrm{M}_{3}$ \\
$\mathrm{M}_{1} \mathrm{M}_{2} \mathrm{M}_{3}$ \\
\end{tabular} & - & - & - & 11 \\
\hline 3 & 90 & $\mathrm{M}_{3} \mathrm{M}_{1}$ & $\frac{\mathrm{M}_{1} \mathrm{M}_{2} \mathrm{M}_{3}}{\mathrm{M}_{1} \mathrm{M}_{2}}$ & - & - & - & 7 \\
\hline 4 & 63 & & $\begin{array}{l}\mathrm{M}_{2} \\
\mathrm{M}_{2}\end{array}$ & $\overline{\mathrm{M}_{2}}$ & - & - & 3 \\
\hline 5 & 685 & $\begin{array}{l}\mathrm{M}_{1} \\
\mathrm{M}_{1}\end{array}$ & $\mathrm{M}_{2}$ & - & - & - & 3 \\
\hline 6 & 76 & $\begin{array}{l}\mathrm{M}_{1} \\
\mathrm{M}_{2}\end{array}$ & $\begin{array}{l}\mathrm{M}_{1} \mathrm{M}_{2} \\
\mathrm{M}_{1} \mathrm{M}_{2} \\
\end{array}$ & - & $\mathrm{M}_{1}$ & - & 7 \\
\hline 7 & 46 & $\mathrm{M}_{2}$ & $\mathrm{M}_{1}$ & \multirow{2}{*}{$\frac{1}{2} M_{1}$} & \begin{tabular}{l|l} 
& \\
$M_{1}$ & $M_{2}$ \\
\end{tabular} & $\square$ & 5 \\
\hline & otal & & 6 & & 5 & 0 & 40 \\
\hline
\end{tabular}

recalled that this feed contains the rice bran and if we can assume that it has effects, though yet uncertain whether singly or in composition with some other substance, to inhibit the caries formation, it should receive attention from dental phamacology in view of the fact that the majority of people in Asia including the Japanese chiefly live on rice. On the other hand, as regards the latter in which polished rice was fed to the animals the development of caries was much promoted in comparison with control. And since polished rice is deficient in nutrition compared with the Oriental feed (Fig. 2 ), the animals were irregular in the weight increment as shown by the curves. It is inferred that polished rice which was converted in the body into glucose was concerned with the mechanism of caries formation. 
TABLE $5(\mathrm{a})$

A Table showing the Caries Formation and its Degrees of Intensity in 13 Experimental Rats (B Additive)

B Additive (Powdered salamander)

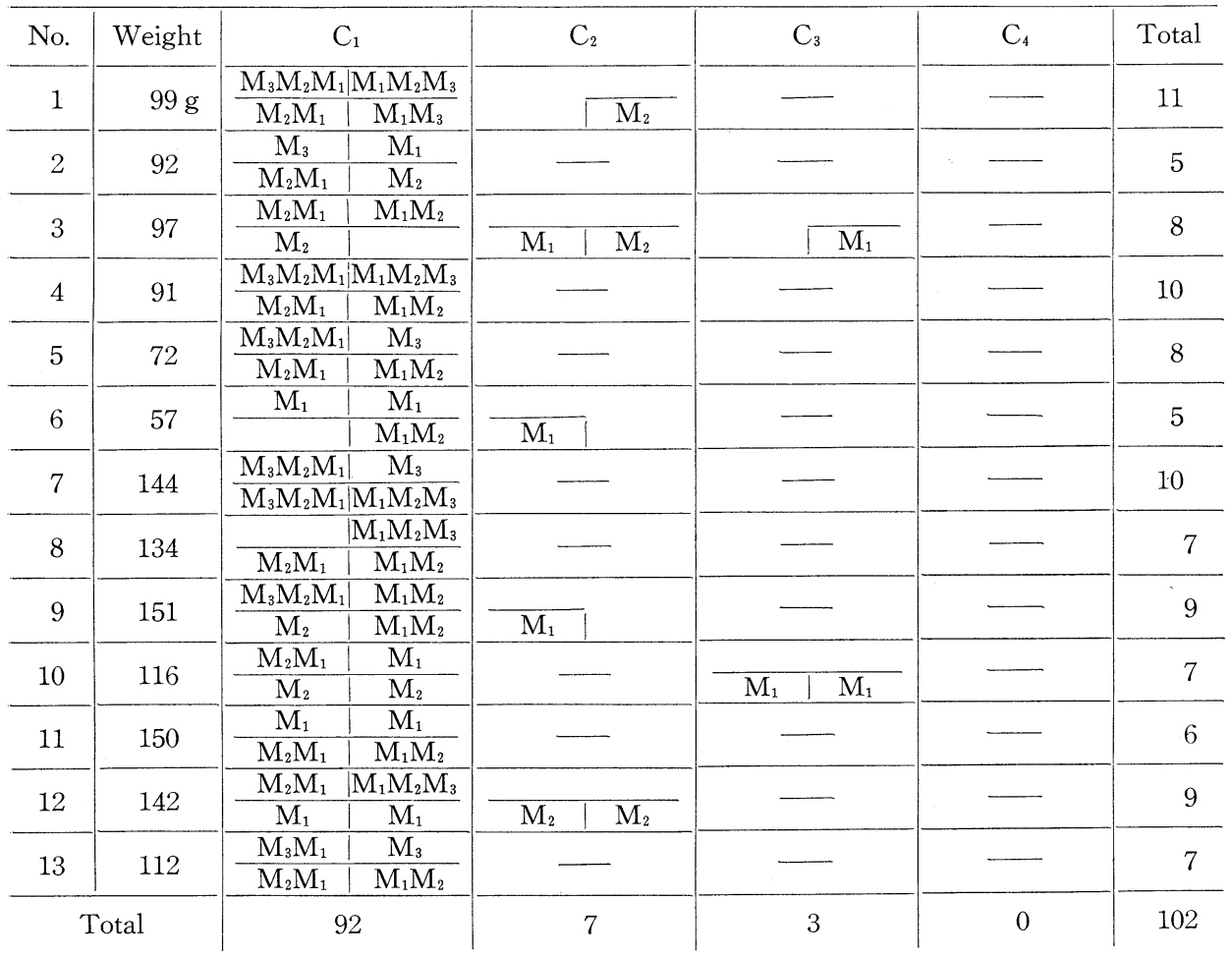

When $\mathrm{A}$ and $\mathrm{B}$ Additives were respectively mixed with the feed, the effects on the caries formation came out as follows (Fig. 4). Although both have remarkable effects in promoting the growth of animals, A Additive (Glycrrhizae Radix) works conducively to the caries formation while B Additive (powdered salamanders) is inhibitive of it. Fluctuations in the occurrence curves below are to be accounted for by seasonal variation in the mechanism of caries formation.

Effects of a feed together with these two additives on the caries formation on an individual basis are shown by Tables 3,4 and 5 .

\section{Possible Effects of Additives on the Various Organ Increments.}

Under this part of our experiment, serial measurements had been taken on the liver, kidney, pancreas, testes and uterus in terms of nutritious effects by the Oriental feed and polished rice (Figs. 5, 6, 7, 8 and 9).

As regards increase in the weight of liver, polished rice feed influenced on the weight increase merely to a half of the case of Oriental feed but there was observed no difference in terms of sex. The same tendency was also seen for kidney and pancreas. However, what is noteworthy here is the fact that polished rice seemed to 
TABLE $5(b)$

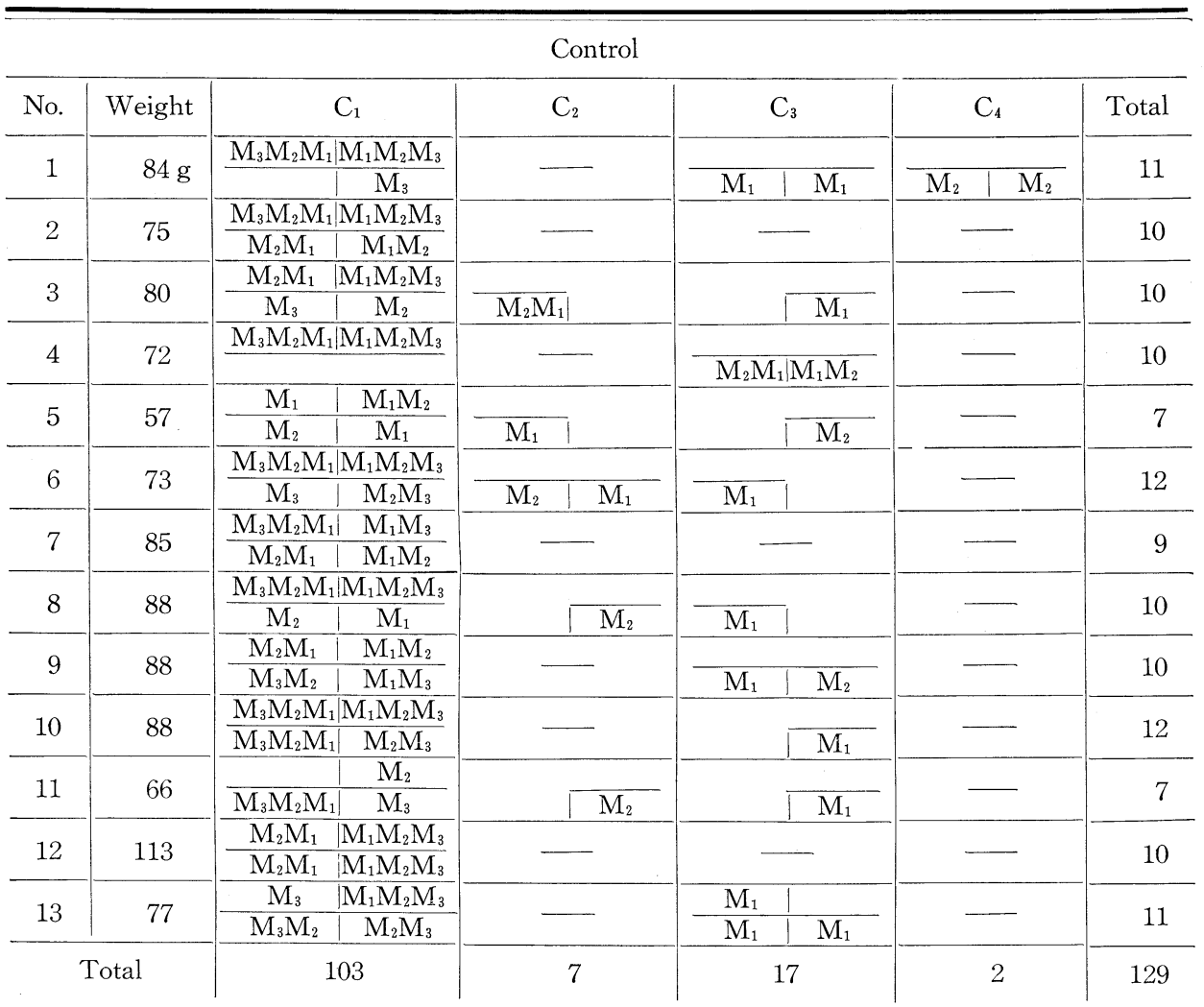

have a favorable effect in enlarging pancreas, the curve especially pronounced in female rats. This may be explained in connection with the known properties of the pancreatic function which generates the red and white corpuscles and takes charge of iron metabolism.

With reference to testes and uterus, no particular findings were noticed but it must be mentioned that the addition of a small amount of additives proved particularly favorable to the weight increase of uterus in experimental animals.

Tables 6 and 7 summarize various results obtained under this head of experiments.

\section{Statistical Treatment of the Measured Values.}

The measured values of the experimental group and those of control were respectively subjected to statistical treatment in an effort to calculate a significant difference between two sets of various values. Statistical treatment was based on the assumption that each set or group of values contained a regular population and from these samples were derived at random for calculational purposes. In the first place, $\delta \mathrm{x}=\delta \mathrm{y}$ was assigned to the values of each group and as most of the measured values did not show regularity, recourse was had to the $\mathrm{T}$ distribution for the determination of a significant difference.

Without delving into unnecessary technical details, an illustration is drawn from 


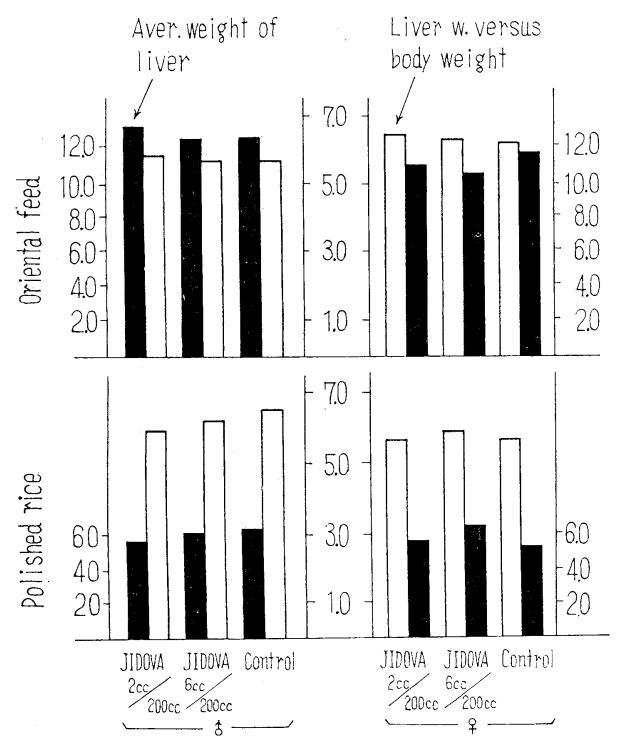

Fig. 5. Effects on the Increment of Liver

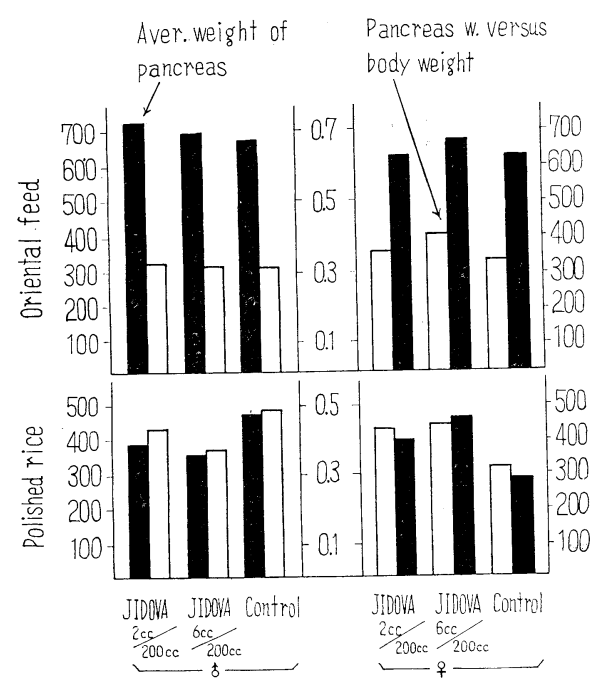

Fig. 7. Effects on the Increment of Pancreas

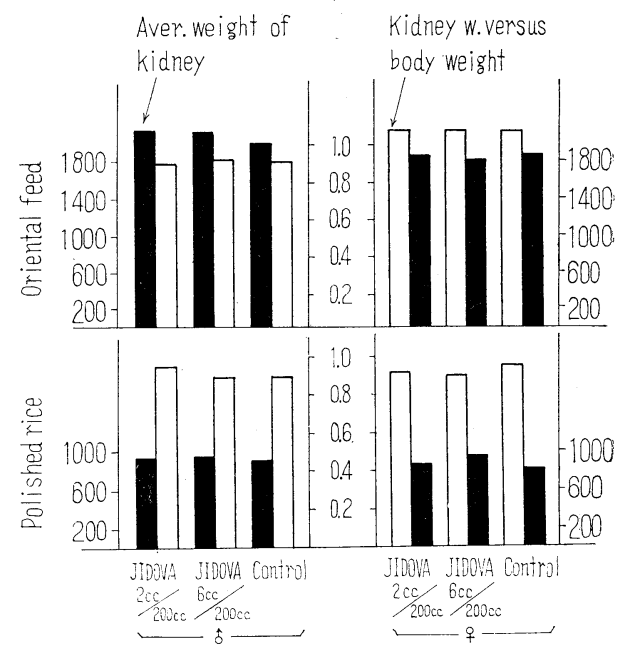

Fig. 6. Effects on the Increment of Kidney
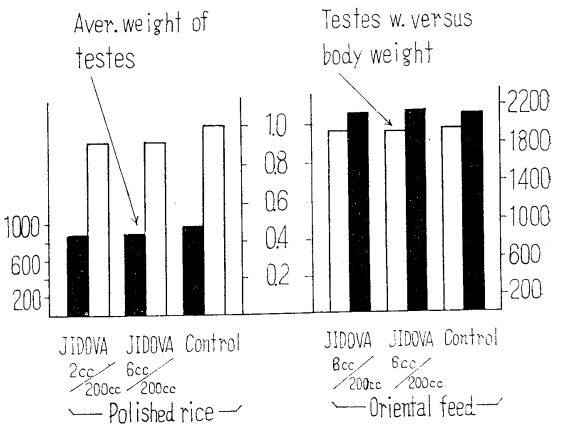

Fig. 8. Effects on the Increment of Testes

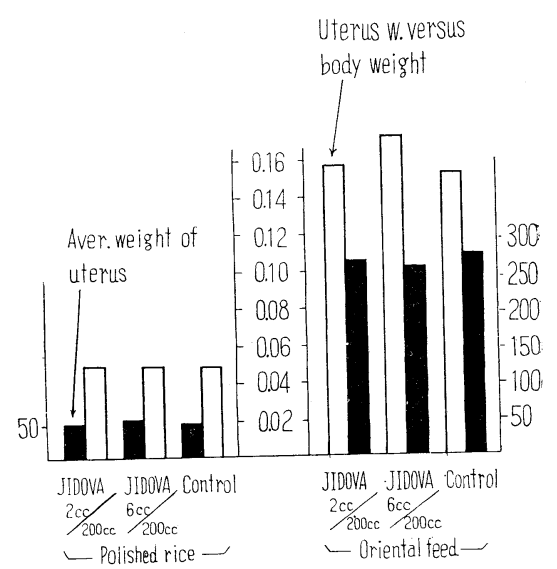

Fig. 9. Effects on the Increment of Uterus 


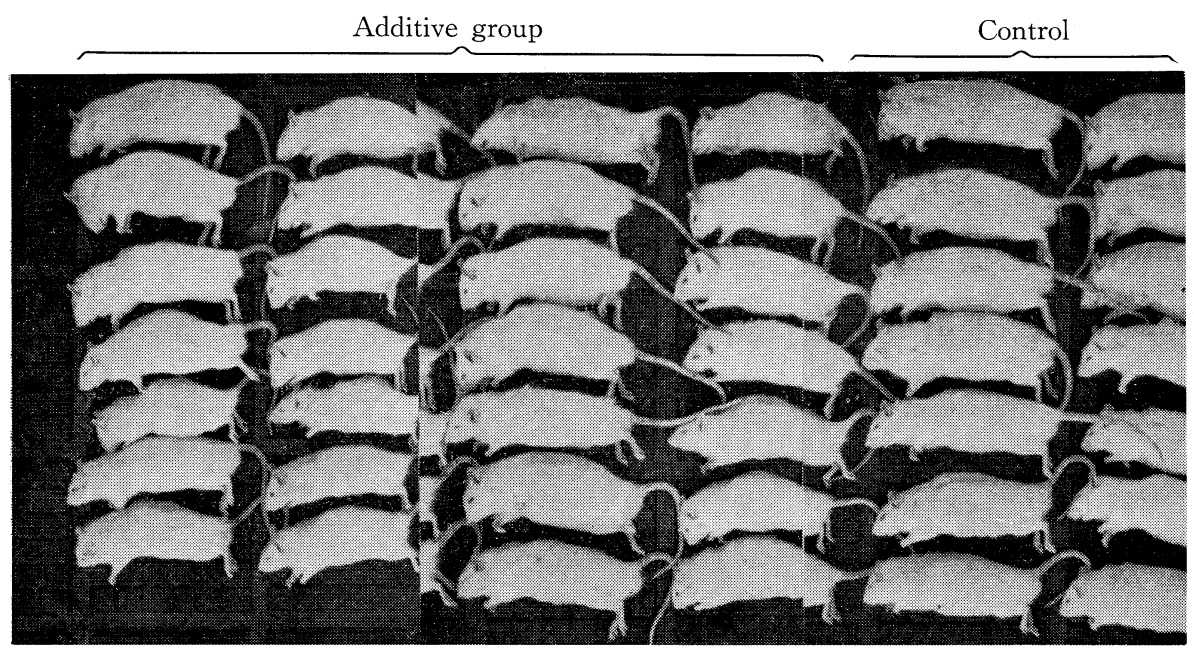

Fig. 10. Weight Increase in Experimental Rats fed on Oriental Perfect Feed

Additive group

Control

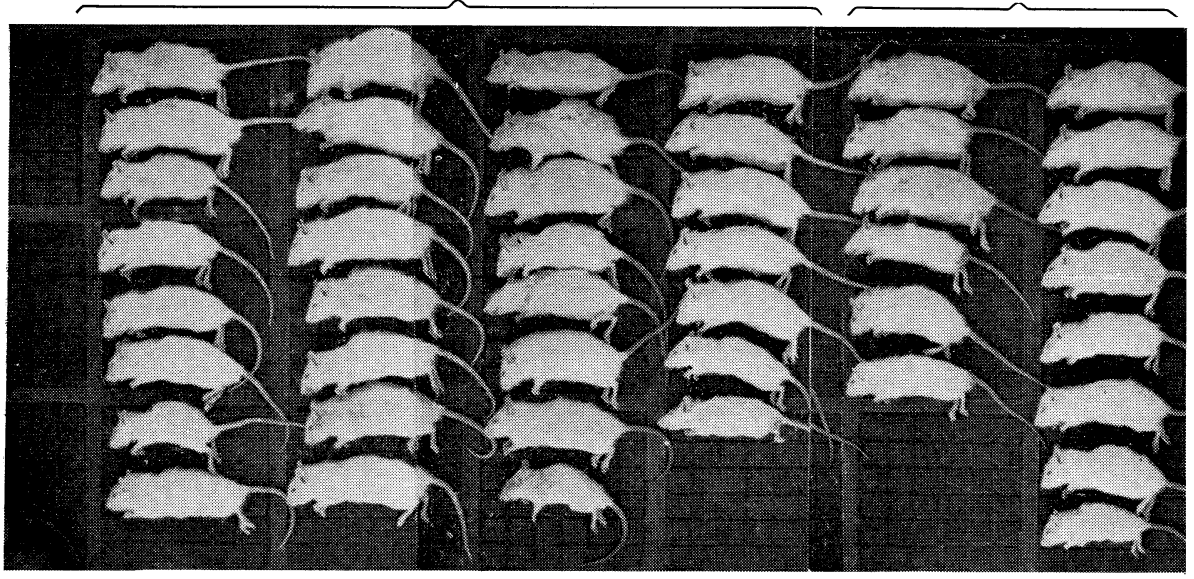

Fig. 11. Weight Increase in Experimental Rats fed on Polished Rice

the determination of a significant difference between the two groups of male rats which were fed on the Oriental perfect feed and polished rice respectively, a ratio of additives against the feed being $2 \mathrm{cc} / 200 \mathrm{cc}$ (Table 6). In the following equations, $\overline{\mathrm{x}}$ and $\overline{\mathrm{y}}$ stand for the measured values of experimental groups, $\mathrm{Nx}$ and $\mathrm{Ny}$ are the number of samples and $\mathrm{Mx}$ and $\mathrm{My}$ are assumed regular population of control.

a. Inspection of uniform diffusion.

$\mathrm{S}_{\mathrm{x}}{ }^{2}=2 \mathrm{cc} / 200 \mathrm{cc}$ group diffusion $=0.69 \quad \mathrm{~S}_{\mathrm{y}}{ }^{2}=$ control diffusion $=0.53$

$\frac{\mathrm{S}_{\mathrm{x}}{ }^{2}}{\mathrm{~S}_{\mathrm{y}}{ }^{2}}=\frac{0.69}{0.53}=1.30 \quad \mathrm{~F}_{\phi_{2}=6}^{\phi_{1}=6} \mathrm{P}_{\gamma}(0.05)=4.28>1.30$

Not significantly different, i. e., $\delta \mathrm{x}=\delta \mathrm{y}$. 


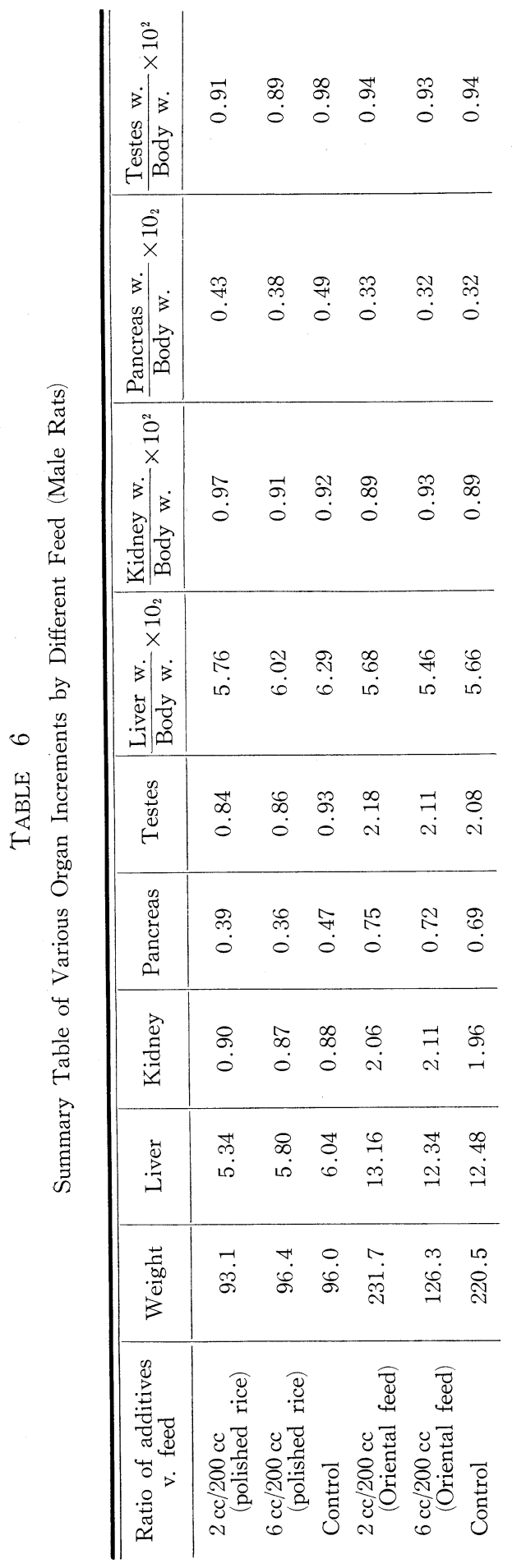

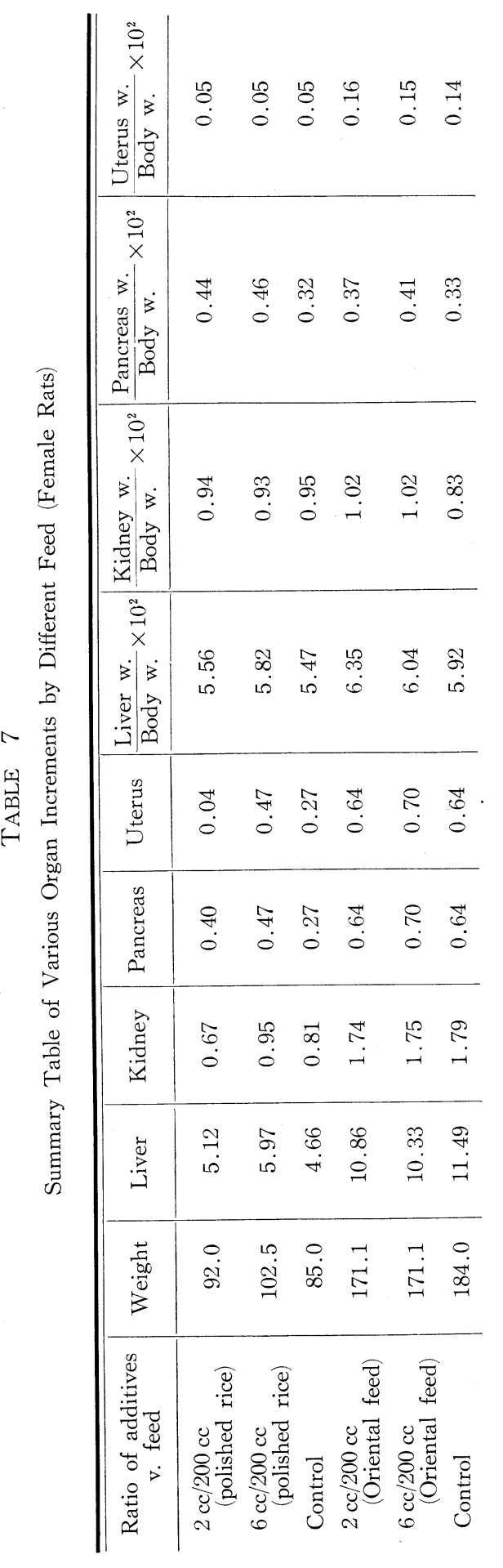


b. Determination of a significant diffusion. $\mathrm{m}_{\mathrm{x}}-\mathrm{m}_{\mathrm{y}}=0$ is assumed in the first place

$$
\begin{aligned}
& \frac{(\overline{\mathrm{x}}-\overline{\mathrm{y}}) \sqrt{\mathrm{n}-1}}{\sqrt{\mathrm{S}_{\mathrm{x}}{ }^{2}+\mathrm{S}_{\mathrm{y}}{ }^{2}}}=\frac{(1.14-1.43) \sqrt{7-1}}{\sqrt{0.69+0.53}}=-\frac{0.29 \sqrt{6}}{\sqrt{1.22}}=-\frac{0.71}{\sqrt{1.22}}=-0.65 \\
& \mathrm{~T}^{\phi=12} \mathrm{p}_{\gamma}\left(|\mathrm{t}|>\mathrm{t}_{\alpha}\right) \\
& \mathrm{T}^{\phi=12} \mathrm{p}_{r}(0.05)=2.18>|0.65| \quad \text { Not significantly different } \\
& \mathrm{T}^{\phi=12} \mathrm{p}_{\gamma}(0.10)=1.78>|0.65| \quad \text { Not significantly different }
\end{aligned}
$$
of risk.

A significant difference is observed neither at $5 \%$ level of risk nor at $10 \%$ level

In this manner, a significant difference was calculated for each group of experimental values and the most prominent significant difference was found to exist between the male rats fed on polished rice $(6 \mathrm{cc} / 200 \mathrm{cc})$ and control, the incidence of dental caries in the former being larger by a long shot. Besides this set of values, that of female rats under the same feeding conditions showed a slight degree of significant difference, no other significant differences observable among the rest.

\section{Considerations}

Male and female rats were experimentally fed on the feed preparation which consisted of Actinidae Fructus, Extractum Ginseng, Epimedii Herba, honey, sugar and millet-jelly in the proportion of $100,1.0,1.5,40,100$ and 40 and on polished rice in an attempt at looking into their effects on the living rats with reference to the incidence of dental caries. In comparison with those fed on polished rice, the rats which were fed on this Oriental perfect feed showed an inhibitory effect of dental caries, the effect being much pronounced in female rats where nearly $1 / 3$ was reduced than otherwise. In addition to the incidence of dental caries, we also observed increment in the various organs such as the liver, kidney, pancreas, testes and uterus including the overall weight. Compared with the values of the rats fed on polished rice, those fed on the Oriental perfect feed showed a greater degree of increment and the increment was most remarkable in the growth of the uterus. However, no possible relationship between the organs has been noticed. When the additives prepared from Glycyrrhizae Radix and powdered salamanders were respectively mixed with the feed, the former was found to be promotive of the formation of dental caries while, on the other hand, the latter was inhibitive of the same phenomenon to a large extent.

\section{References}

[1] Yamashita et al. : Article published in the Junten-do Medical Journal (Jap. text), 5, 339 (1959)

[2] Tsuchiy et al. : Article published in the Journal of Industrial Chemistry (Jap. text), 57, 7 (1957)

[3] Hashizume et al. : A Collection of Papers on Pharmacology (Jap. text), p. 6, 1958, Tokyo Pharmaceutical Co.

[4] T. TAmURA: Article published in Shika-Geppo (Jap. text), 32, 1 (1958)

[5] Ditto: J. Nihon Univ. Sch. Dent., 4, 125 (1962) 